\title{
The predictive value of the Sokal and Hasford scoring systems in chronic myeloid leukaemia in the imatinib era
}

\author{
Oyekunle AA ${ }^{1,2}$, Osho PO ${ }^{1}$, Aneke J C $^{1}$, Salaw u L ${ }^{1,2}$, Durosinmi MA ${ }^{1,2}$ \\ 1. Department of Hematology and Blood Transfusion, Obafemi Awolowo University Teaching Hospitals, Ile-Ife, Nigeria. \\ 2. Department of Hematology and Immunology, Obafemi Awolowo University, Ile-Ife, Nigeria
}

Correspondence: Anthony Oyekunle. Address: Department of Hematology and Immunology, Obafemi Awolowo University (OAU), Ile-Ife, Nigeria. Telephone: 234-803-239-8360. E-mail: oyekunleaa@yahoo.co.uk

Received: May 3, 2012

DOI : $10.5430 /$ jhm.v2n2p25
Accepted: May 24, 2012

URL: http://dx.doi.org/10.5430/jhm.v2n2p25

Published: June 1, 2012

\section{Abstract}

Objectives: Chronic myeloid leukemia (CML) is a clonal myeloproliferative disorder characterized by the presence of Philadelphia chromosome $(\mathrm{Ph})$ or $B C R-A B L 1$ chimeric gene; which codes for an abnormal tyrosine kinase responsible for the malignant proliferation of myeloid cells. Imatinib mesylate, a selective inhibitor of this kinase, is the first choice of therapy in patients with CML. The study aimed to determine the effect of imatinib on the survival of different risk groups based on the Sokal and Hasford scoring systems.

Methods: Between August 2003 and December 2009, 134 patients [83 males (62\%), 51 females (38\%)] who came in first chronic phase (CP1) were recruited. Median age was 36 years (Range, 13 - 75). Patients were followed up with monthly complete blood counts. Karyotyping and chemistries were done at 6 and 12 months into therapy and then yearly. Overall survival (OS), progression-free survival (PFS) and frequency of complete cytogenetic remission (CCR) were evaluated. Survival studies were analyzed using the Kaplan- Meier technique and $P$-value $<0.05$ was considered significant.

Results: OS was $99 \%$ and $94 \%$, while PFS was $95 \%$ and $83 \%$, at one and two years respectively. Both the Sokal and Hasford risk groups predicted significantly better PFS for low- and intermediate-risk patients $(P=0.012$ and $P=0.0001$ respectively). However, neither of the scores was predictive for differences in OS or CCR.

Conclusions: These results suggests that the Sokal and Hasford scoring systems are inadequate in predicting OS and CCR of CML patients in CP1 managed on imatinib, as compared to their usefulness before the imatinib era.

\section{Key words}

Chronic myeloid leukemia, Imatinib mesylate, Sokal and Hasford score, Overall survival, Progression-free survival

\section{I ntroduction}

Chronic myeloid leukemia (CML) is a clonal hematopoietic disorder characterized by the malignant expansion of bone marrow stem cells. Its cytogenetic hallmark is a reciprocal $\mathrm{t}(9 ; 22)(\mathrm{q} 34 ; \mathrm{q} 11)$ chromosomal translocation that creates a derivative $9 \mathrm{q}+$ and a small $22 \mathrm{q}-$, known as the Philadelphia chromosome $(\mathrm{Ph})^{[1]}$. The latter harbors the BCR-ABL1 fusion gene encoding a chimeric protein with a deregulated tyrosine kinase activity, the expression of which has been shown to be necessary and sufficient for the transformed phenotype of CML cells ${ }^{[1]}$. 
The disease typically runs a biphasic or triphasic course, but a large majority of patients are detected in the chronic phase. Treatment of CML has evolved over the past decades from the use of total body irradiation, to the use of cytoreductive agents (busulphan and hydroxyurea) which can achieve hematologic control. Interferon-alpha (IFN- $\alpha$ ), either alone or in combination with cytarabine, has been associated with both hematologic and cytogenetic response. To date, only allogeneic stem cell transplantation (SCT) remains curative ${ }^{[2]}$, though its role has waned significantly in recent times due to the relative safety and effectiveness of the tyrosine kinase inhibitors ${ }^{[3]}$. Although potentially curative, SCT is associated with significant morbidity and mortality ${ }^{[4]}$. Alpha interferon-based regimens adequately control chronic phase disease, but result in few long term survivors ${ }^{[5]}$.

Recent advances in targeted therapy resulted in the discovery of imatinib mesylate, a selective competitive inhibitor of $B C R-A B L 1$ protein tyrosine kinase, which has been demonstrated to induce both haematologic and cytogenetic remission in a significant proportion of CML patients ${ }^{[6]}$. Comparison with historical controls show improved survival, even in the later stages of the disease ${ }^{[7,8]}$ for patients treated with imatinib.

Several prognostic scoring systems have been developed for patients with CML, of which the Sokal and Hasford (Or Euro)

scores are the most popular ${ }^{[9-11]}$. The Sokal score was generated using chronic phase CML patients treated with busulphan or hydroxyurea, while the Hasford score was derived and validated, using patients treated with IFN- $\alpha$. The aim of this study was to determine the effect of imatinib on the survival pattern of patients with CML, in different Sokal and Hasford risk groups.

\section{Subjects and methods}

This study was registered and approved by our local hospital's ethics and research committee. All patients gave written informed consent before recruitment to the study. It included all confirmed cases of $\mathrm{Ph} / B C R$-ABL1-positive CML in first chronic phase managed with imatinib in our unit between August 2003 and December 2009. Only patients who have been on imatinib for at least three months were recruited. Parameters including the age, spleen size (Below the costal margin), percent blast, platelets, eosinophil, basophil and neutrophil counts at presentation, were retrieved from the case notes. The Sokal and Hasford scores, calculated using previously published formulae ${ }^{[10,11]}$, was used to classify the patients into different risk groups. All patients were commenced on imatinib at $400 \mathrm{mg} /$ day and monitored for tolerance and side effects while on therapy. Stepwise dose escalation to a maximum of $800 \mathrm{mg} / \mathrm{day}$ was considered in case of any of the following: Failure to achieve a complete hematological response (CHR) by 3 months, a major cytogenetic remission (MCR) at 6 months, and a complete cytogenetic remission (CCR) at 12 months. The patients were monitored with physical examinations and complete blood counts on day 1 of therapy and monthly thereafter. Cytogenetic response was assessed using bone marrow karyotype studies done every 6 months until patients achieve a CCR, and repeated annually thereafter. Patients with features of sub-optimal and failed response, or disease progression were investigated for the presence of ABL1 kinase domain mutations, some of which have been previously reported ${ }^{[12]}$.

Women of child-bearing age were advised to use barrier contraception, and to inform us as soon as they observed a prolongation of their menstrual cycle. Imatinib was withdrawn for variable periods in patients who develop neutropenia $(<$ $\left.1000 / \mathrm{mm}^{3}\right)$ or thrombocytopenia $\left(<75,000 / \mathrm{mm}^{3}\right)$ while on therapy, until the cytopenias were corrected, and they were re-commenced at lower doses. Hematologic and cytogenetic responses were defined as in recent reports ${ }^{[6,13-15]}$.

Overall survival (OS) was defined as the interval from the start of imatinib therapy to death from all causes. Disease progression was defined as the development of any of the following: Loss of cytogenetic response, progression to accelerated or blastic phase and death from all causes. All other patients were censored on the date of last follow-up. Time 
from diagnosis to achievement of CCR was analyzed according to risk groups. Cox regression analysis was deployed to examine the impact of the Sokal and Hasford risk groups on the OS and PFS endpoints.

\section{Results}

This study recruited 134 patients, with median age of 36 years (Range, 13 - 75) at diagnosis. There were 83 males (62\%) and 51 females (38\%). The median time from diagnosis to start of imatinib therapy was 89 days. Median spleen size $(\mathrm{BCM})$ was $14.0 \mathrm{~cm}$; other parameters at diagnosis are shown in Table 1.

Table 1. Characteristics of 134 patients with chronic myeloid leukemia in chronic phase, at diagnosis

\begin{tabular}{llll}
\hline Varibles & Median & Range & S.D \\
\hline Age $($ yrs $)$ & 36 & $13-75$ & 14.0 \\
Hematocrit $(\%)$ & 32 & $14-49$ & 6.7 \\
WBC count $\left(\times 10^{9} / \mathrm{L}\right)$ & 135 & $3-664$ & 150.0 \\
Peripheral blast $(\%)$ & 3.0 & $1-8$ & 2.0 \\
Basophil $(\%)$ & 3.0 & $1-10$ & 2.3 \\
Eosinophil $(\%)$ & 2.0 & $1-11$ & 2.6 \\
Platelet count $\left(\times 10^{9} / \mathrm{L}\right)$ & 220 & $45-600$ & 137.1 \\
Spleen size $(\mathrm{cm}, \mathrm{BCM})$ & 14.0 & $3-31$ & 6.8 \\
Liver size $(\mathrm{cm}, \mathrm{BCM})$ & 7.0 & $2-14$ & 3.3 \\
Days from diagnosis to start of imatinib & 8.9 & $7-1638$ & 314.4 \\
\hline Abbreviations: SD= & &
\end{tabular}

Abbreviations: $\mathrm{SD}=$ standard deviation; $\mathrm{BCM}=$ below costal margin

All patients received hydroxyurea between diagnosis of CML and the confirmation of a positive $\mathrm{Ph}$ status $(\mathrm{n}=121)$ or BCR-ABL1 fusion gene transcript $(\mathrm{n}=13)$, before commencing imatinib. At diagnosis, $54(40.3 \%), 45(33.6 \%)$ and 35 (26.1\%) patients were in the Sokal low, intermediate and high risk groups respectively; while 72 (53.7\%), 49 (36.6\%) and $13(9.7 \%)$ patients were in the Hasford low, intermediate and high risk groups respectively.

At the time of analysis, 119 (88.8\%) were alive and on imatinib, 10 having died from disease progression, and three died after more than six months of being lost to follow-up. One patient died from severe malaria while on a long-distance travel, and another died from injuries sustained from a road traffic accident. Disease progression was noted in 28 (20.9\%) patients; 14 to accelerated phase (AP), 10 to blastic phase (BP), and four lost cytogenetic response (CR). All were managed with imatinib dose escalation, with favorable responses in three BP and $10 \mathrm{AP}$ cases, and in all that lost CR. One patient, who had an E255K mutant clone, did not respond, and was eventually commenced on nilotinib. Two of our patients were referred to have stem cell transplantation, but it was not done due to lack of suitably matching donors.

Overall survival (OS) for all patients was $99 \%$ and $94 \%$, while PFS was $95 \%$ and $83 \%$ at one and two years, respectively (Figure 1). The Sokal score was not predictive of differences in the OS of patients but sufficiently differentiates the PFS of patients in the risk groups ( $P=0.042$, Figure $2 \mathrm{~A})$. The Hasford scoring system performed better as the positive predictive value is more statistically significant for differences in PFS ( $P=0.001$, Figure $2 \mathrm{~B})$; but it also fails to predict differences in OS. These PFS differences are even more pronounced if the low and intermediate risk groups are combined and compared to the high risk group (Sokal, $P=0.012$; Hasford, $P=0.0001$ ).

Complete cytogenetic remission (CCR) rates at one and 2 years were $33 \%$ and $68 \%$ respectively, though the two scoring systems did not correlate with differences in the CCR rate. 

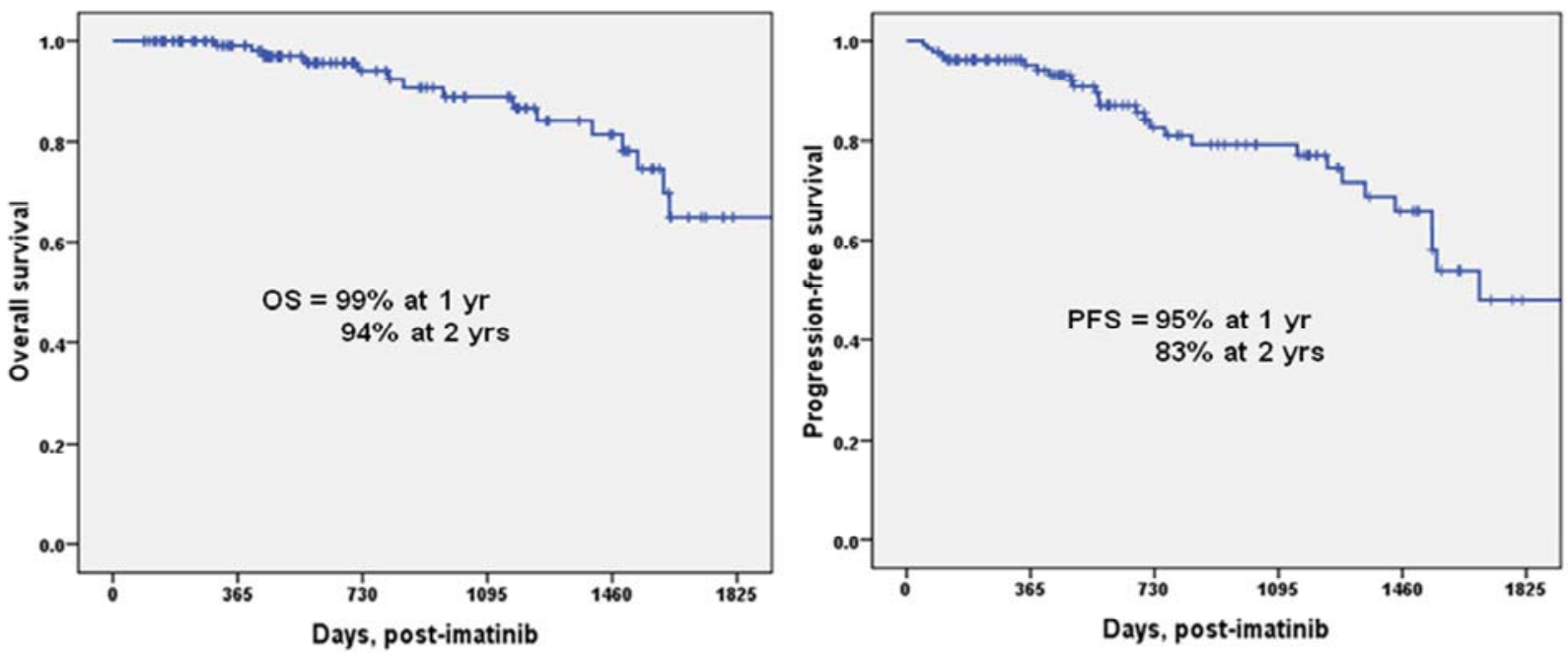

Figure 1. Overall survival (OS) and progression-free survival (PFS) of $134 \mathrm{CML}$ patients

Panel A.
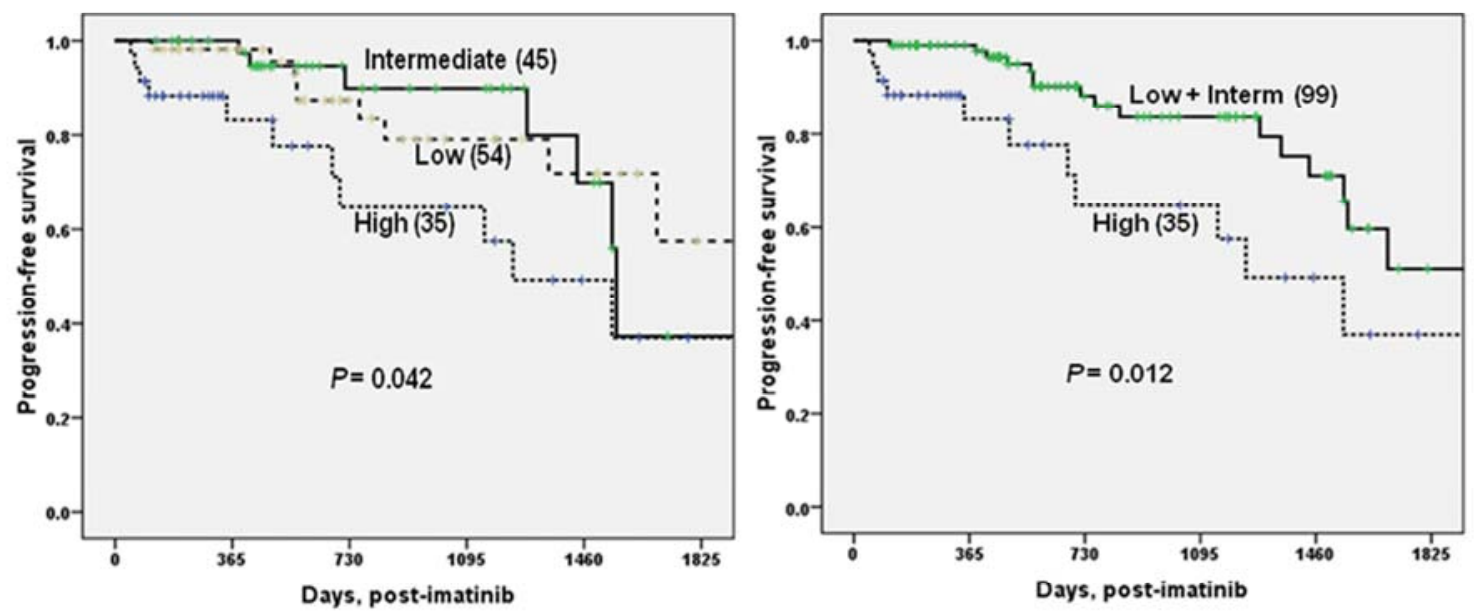

\section{Panel B.}
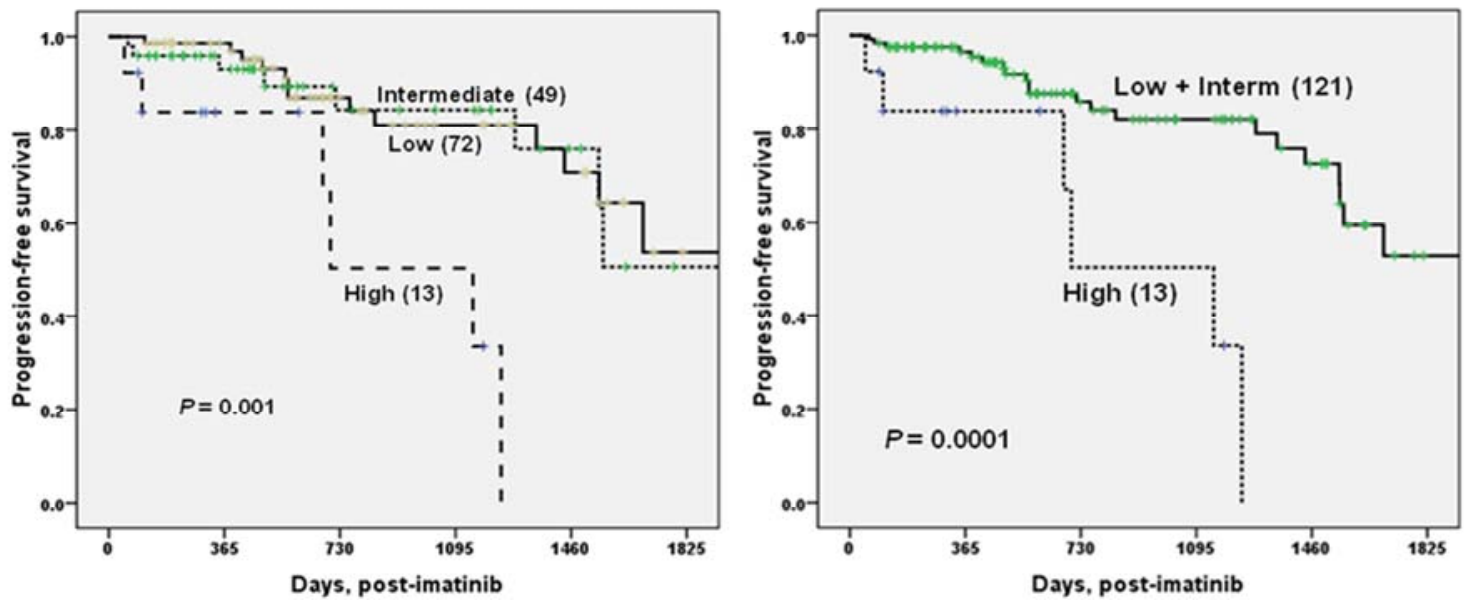

Figure 2. Progression-free survival (PFS) of all patients, according to the Sokal (Panel A) and Hasford (Panel B) risk groups 


\section{Discussion}

The OS and PFS for these patients, all in CP1, is expectedly better than what was earlier reported from our centre using imatinib $^{[16]}$, in which we had considered all phases of CML. Also the OS for the different risk categories for both scoring systems were better than those reported in the original studies by Sokal and Hasford, in spite of the short follow-up period ${ }^{[10,11]}$. This further confirms the advantage of imatinib over previously used chemotherapeutic agents.

The median time from diagnosis to commencement of imatinib was relatively long, at 13 weeks, and it is known that this can contribute to a worse prognosis and reduce the probability of response ${ }^{[16]}$. Despite this, the overall survival at one year was $99 \%$ which was impressive in an African population. This however, dropped to $65 \%$ at 5 years which is low compared to $89 \%$ reported in previous studies of European and American patients ${ }^{[7,17]}$. This may be a reflection of limited number of patients involved in this study, as only 5 patients are left in the study at that time point. It may also be a reflection of poor adherence to the daily imatinib regimen in our patients, though we have not been able to objectively assess drug adherence in our cohort.

The results from this study have also shown that the diagnostic parameters used in the Sokal and Hasford scores may need to be reviewed, if they are to retain their prognostic relevance in the imatinib era, especially as regards predicting OS and CCR rates. However, the scores appear to remain useful for predicting disease progression, judging by the significantly worse PFS of patients in the high risk groups. In this regard, the Hasford score performed better than the Sokal score, and the patients can readily be segregated into high and non-high risk groups, with better differentiation.

Though few authors have considered the effect of these scoring systems on survival, Larson et al. ${ }^{[18]}$ had also shown that imatinib plasma levels correlated with CCR, major molecular response (MMR) and event-free survival (EFS) rates in CML, independent of the Sokal risk score. Other studies have also failed to show the effect of age on response rates and survival outcomes in the imatinib era. Gugliotta et al. ${ }^{[19]}$ examined the effect of age on OS and PFS in the imatinib era and reported that response was not affected by age; while Usman et al. ${ }^{[20]}$ were also unable to find an advantage in response rates for younger patients. This work was considered rather important as age is one of the cardinal variables in these two scoring systems. On the contrary though, Hughes et al. ${ }^{[21]}$ showed that both the Sokal and Hasford scoring systems are still important in predicting OS, CCR and molecular response rates. In their study, the Sokal scoring system showed more discrimination between the risk groups than the Hasford score, but showing very little difference in their CCR rates. In another study, Aziz et al. ${ }^{[22]}$ reported that low Sokal score (Among other factors) was a significant predictive factor for event-free survival (EFS); which is similar to what we have observed in this study.

In an attempt to determine other useful diagnostic variables, we examined the impact of disease duration at time of starting imatinib, but it did not show any survival advantage for those whose duration was $<90$ days. This agrees with the outcome of the study by Usman et al. ${ }^{[20]}$ which found that disease duration at time of starting imatinib failed to show any significant influence on response to imatinib, though response rates were higher in patients who had low Sokal scores. The authors concluded that being in the Sokal low risk group predicts for higher response rates.

Other studies have found that the impact of the Sokal risk on the mortality of chronic phase CML patients is related to the period of therapy ${ }^{[23,24]}$. Corm et al. found that since year 2000 , the mortality of patients in intermediate-risk and high-risk groups became similar. In fact, Kantarjian et al. reported that survival by Sokal risk groups was significantly different before $2001(P<0.001)$, but not since $2001(P=0.4)^{[23]}$.

Simonsson et al. in 2005 further demonstrated that the Sokal risk groups had significantly different overall survival $(P<$ $0.001)$ and $C C R$ rate $(P=0.002)$; though the difference is lost following achievement of $\mathrm{CCR}^{[25]}$ This might imply that the baseline prognostic factors may lose their significance after CCR, and may partly explain their limited impact on survival outcomes. Simonsson's preliminary results laid the initial groundwork for a school of thought that the long-term prognosis 
of CML patients on imatinib may be more dependent on post-recruitment variables such as time required to achieve CHR and $\mathrm{CCR}$, and more recently major molecular response ${ }^{[16,26,27]}$.

However, several other researchers have been accumulating evidence that seems to support a more important role for gene expression profiling; and that these genetic profiles are probably more informative approaches to predicting overall disease duration ${ }^{[28-30]}$.

In 2011, a group of European centres published a new prognostic scoring system (EUTOS) that is reportedly superior to the Sokal and Euro scores both in its prognostic ability and in its simplicity. The EUTOS score was based on spleen size and basophil counts at diagnosis, and it had significant discriminatory powers in predicting for CCR at 18 months; a feat that was impossible using the Sokal and Euro scores ${ }^{[31]}$. At least two independent groups of researchers have been unable to replicate its utility in their patient cohorts ${ }^{[32,33]}$.

\section{Conclusion}

Our result suggests that the Sokal and Hasford scoring systems are not as effective in predicting OS and CCR rates for CML patients on imatinib, as compared to their usefulness with the cytoreductive agents and interferon- $\alpha$. However with similar studies showing some usefulness, coupled with their ability to show significant differences in PFS among the risk groups, they still remain useful in predicting disease progression of CML patients on imatinib; but their applicability may be subject to other yet unknown local, environmental and genetic variations

\section{Conflict of interest}

The authors declare that there is no conflict of interest statement.

\section{References}

[1] Melo JV, Hughes TP, Apperley JF. Chronic myeloid leukemia. ASH Hematology. 2003:132-52.

[2] Robin M, Guardiola P, Devergie A, Yeshurun M, Shapiro S, Esperou H, et al. A 10-year median follow-up study after allogeneic stem cell transplantation for chronic myeloid leukemia in chronic phase from HLA-identical sibling donors. Leukemia. 2005;19(9):1613-20. PMid:15990868 http://dx.doi.org/10.1038/sj.leu.2403821

[3] Oyekunle A, Klyuchnikov E, Ocheni S, Kroger N, Zander AR, Baccarani M, et al. Challenges for Allogeneic Hematopoietic Stem Cell Transplantation in Chronic Myeloid Leukemia in the Era of Tyrosine Kinase Inhibitors. Acta Haematologica. 2011;126(1):30-39. PMid:21411987 http://dx.doi.org/10.1159/000323662

[4] Gratwohl A, Hermans J, Goldman JM, Arcese W, Carreras E, Devergie A, et al. Risk assessment for patients with chronic myeloid leukemia before allogeneic blood or marrow transplantation. Chronic Leukemia Working Party of the European Group for Blood and Marrow Transplantation. Lancet. 1998;352(9134):1087-92. http://dx.doi.org/10.1016/S0140-6736(98)03030-X

[5] Bonifazi F, de Vivo A, Rosti G, Guilhot F, Guilhot J, Trabacchi E, et al. Chronic myeloid leukemia and interferon- $\alpha$ : A study of complete cytogenetic responders. Blood. 2001 November 15, 2001;98(10):3074-81.

[6] Kantarjian H, Sawyers C, Hochhaus A, Guilhot F, Schiffer C, Gambacorti-Passerini C, et al. Hematologic and cytogenetic responses to imatinib mesylate in chronic myelogenous leukemia. N Engl J Med. 2002;346(9):645-52. PMid:11870241 http://dx.doi.org/10.1056/NEJMoa011573

[7] Talpaz M, Silver RT, Druker BJ, Goldman JM, Gambacorti-Passerini C, Guilhot F, et al. Imatinib induces durable hematologic and cytogenetic responses in patients with accelerated phase chronic myeloid leukemia: Results of a phase 2 study. Blood. 2002 March 15, 2002;99(6):1928-37.

[8] Sawyers CL, Hochhaus A, Feldman E, Goldman JM, Miller CB, Ottmann OG, et al. Imatinib induces hematologic and cytogenetic responses in patients with chronic myelogenous leukemia in myeloid blast crisis: Results of a phase II study. Blood. 2002 May 15, 2002;99(10):3530-39.

[9] Gratwohl A, Brand R, Apperley J, Crawley C, Ruutu T, Corradini P, et al. Allogeneic hematopoietic stem cell transplantation for chronic myeloid leukemia in Europe 2006: Transplant activity, long-term data and current results. An analysis by the Chronic 
Leukemia Working Party of the European Group for Blood and Marrow Transplantation (EBMT). Hematological. 2006;91(4):513-21.

[10] Sokal JE, Cox EB, Baccarani M, Tuna S, Gomez GA, Robertson JE, et al. Prognostic discrimination in "good-risk" chronic granulocytic leukemia. Blood. 1984 April;63(4):789-99.

[11] Hasford J, Pfirrmann M, Hehlmann R, Allan NC, Baccarani M, Kluin-Nelemans JC, et al. A new prognostic score for survival of patients with chronic myeloid leukemia treated with interferon alfa. Writing Committee for the Collaborative CML Prognostic Factors Project Group. J Natl Cancer Inst. 1998 June 3, 1998;90(11):850-58.

[12] Oyekunle AA, Bolarinwa RAA, Owojuyigbe T, Ogbe OP, Salawu L, Faluyi JO, et al. H396R, F359V and E255K mutations of the Abl kinase domain in imatinib-resistant Nigerian patients with chronic myeloid leukemia. Afr J Haem Oncol. 2010;1(3):79-83.

[13] O'Brien SG, Guilhot F, Larson RA, Gathmann I, Baccarani M, Cervantes F, et al. Imatinib compared with interferon and low-dose cytarabine for newly diagnosed chronic-phase chronic myeloid leukemia. N Engl J Med. 2003;348(11):994-1008. PMid:12637609 http://dx.doi.org/10.1056/NEJMoa022457

[14] Rosti G, Martinelli G, Bassi S, Amabile M, Trabacchi E, Giannini B, et al. Molecular response to imatinib in late chronic-phase chronic myeloid leukemia. Blood. 2004 March 15, 2004;103(6):2284-90.

[15] Baccarani M, Martinelli G, Rosti G, Trabacchi E, Testoni N, Bassi S, et al. Imatinib and pegylated human recombinant interferon- $\alpha 2 b$ in early chronic-phase chronic myeloid leukemia. Blood. 2004 December 15, 2004;104(13):4245-51.

[16] Durosinmi MA, Faluyi JO, Oyekunle AA, Salawu L, Adediran IA, Akinola NO, et al. The use of Imatinib mesylate (Glivec) in Nigerian patients with chronic myeloid leukemia. Cellular Therapy and Transplantation. 2008;1(2):10.3205/ctt-2008-en-000027.01. http://dx.doi.org/10.3205/ctt-2008-en-000027.01

[17] Druker BJ, Guilhot F, O'Brien SG, Gathmann I, Kantarjian H, Gattermann N, et al. Five-Year Follow-up of Patients Receiving Imatinib for Chronic Myeloid Leukemia. N Engl J Med. 2006 December 7, 2006;355(23):2408-17.

[18] Larson RA, Druker BJ, Guilhot F, O'Brien SG, Riviere GJ, Krahnke T, et al. Imatinib pharmacokinetics and its correlation with response and safety in chronic-phase chronic myeloid leukemia: A subanalysis of the IRIS study. Blood. 2008;111(8):4022-28. PMid:18256322 http://dx.doi.org/10.1182/blood-2007-10-116475

[19] Gugliotta G, Castagnetti F, Palandri F, Breccia M, Intermesoli T, Capucci A, et al. Frontline imatinib treatment of chronic myeloid leukemia: No impact of age on outcome, a survey by the GIMEMA CML Working Party. Blood. May 26, 2011;117(21):5591-99. PMid:21450900 http://dx.doi.org/10.1182/blood-2010-12-324228

[20] Usman M, Syed NN, Kakepoto GN, Adil SN, Khurshid M. Chronic phase chronic myeloid leukemia: Response of imatinib mesylate and significance of Sokal score, age and disease duration in predicting the hematological and cytogenetic response. Journal of Association of Physicians India. 2007;55:103-107. PMid:17571738

[21] Hughes TP, Kaeda J, Branford S, Rudzki Z, Hochhaus A, Hensley ML, et al. Frequency of major molecular responses to imatinib or interferon alfa plus cytarabine in newly diagnosed chronic myeloid leukemia. N Engl J Med. 2003;349(15):1423-32. PMid:14534335 http://dx.doi.org/10.1056/NEJMoa030513

[22] Aziz Z, Iqbal J, Bano K, et al. Sustained superior long-term outcomes and cytogenetic responses with imatinib mesylate in chronic phase chronic myeloid leukemia: Report from a developing country. Japan Journal of Clinical Oncology. 2010;40(6):549-55. PMid:20189974 http://dx.doi.org/10.1093/jjco/hyq012

[23] Kantarjian H, O'Brien S, Jabbour E, Garcia-Manero G, Quintas-Cardama A, Shan J, et al. Improved survival in chronic myeloid leukemia since the introduction of imatinib therapy: A single-institution historical experience. Blood. 2012 March 1, 2012;119(9):1981-7.

[24] Corm S, Roche L, Micol J-B, Coiteux V, Bossard N, Nicolini F-E, et al. Changes in the dynamics of the excess mortality rate in chronic phase-chronic myeloid leukemia over 1990-2007: A population study. Blood. 2011 October 20, 2011;118(16):4331-37.

[25] Simonsson B, Oberg G, Bjoreman M, Bjorkholm M, Carneskog J, Karlsson K, et al. Intensive treatment and stem cell transplantation in chronic myelogenous leukemia: Long-term follow-up. Acta Haematol. 2005;113(3):155-62. PMid:15870485 http://dx.doi.org/10.1159/000084445

[26] Marin D, Marktel S, Bua M, Szydlo RM, Franceschino A, Nathan I, et al. Prognostic factors for patients with chronic myeloid leukemia in chronic phase treated with imatinib mesylate after failure of interferon alfa. Leukemia. 2003;17(8):1448-53. PMid:12886230 http://dx.doi.org/10.1038/sj.leu.2402996

[27] Guilhot F, on behalf of IRIS study group. Second line treatment with imatimb after crossover from interferon and plus cytarabine yields high rate of durable response. Results from international randomized study of IFN VS STI571. Blood. 2006;108(11):Abstract no. 2137.

[28] Villuendas R, Steegmann JL, Pollan M, Tracey L, Granda A, Fernandez-Ruiz E, et al. Identification of genes involved in imatinib resistance in CML: A gene-expression profiling approach. Leukemia. 2006;20(6):1047-54. PMid:16598311 http://dx.doi.org/10.1038/sj.leu.2404197 
[29] Frank O, Brors B, Fabarius A, Li L, Haak M, Merk S, et al. Gene expression signature of primary imatinib-resistant chronic myeloid leukemia patients. Leukemia. 2006;20(8):1400-407. PMid:16728981 http://dx.doi.org/10.1038/sj.leu.2404270

[30] Zheng C, Li L, Haak M, Brors B, Frank O, Giehl M, et al. Gene expression profiling of CD34+ cells identifies a molecular signature of chronic myeloid leukemia blast crisis. Leukemia. 2006;20(6):1028-34. PMid:16617318 http://dx.doi.org/10.1038/sj.leu.2404227

[31] Hasford J, Baccarani M, Hoffmann V, Guilhot J, Saussele S, Rosti G, et al. Predicting complete cytogenetic response and subsequent progression-free survival in 2060 patients with CML on imatinib treatment: The EUTOS score. Blood. 2011 July 21 , 2011;118(3):686-92.

[32] Marin D, Ibrahim AR, Goldman JM. European Treatment and Outcome Study (EUTOS) Score for Chronic Myeloid Leukemia Still Requires More Confirmation. Journal of Clinical Oncology. 2011 October 10,2011;29(29):3944-45.

[33] Jabbour E, Cortes J, Nazha A, O'Brien S, Quintas-Cardama A, Pierce S, et al. EUTOS score is not predictive for survival and outcome in patients with early chronic phase chronic myeloid leukemia treated with tyrosine kinase inhibitors: A single institution experience. Blood. 2012 March 19, 2012. 